\title{
A Novel Statistical Based Methodology for the Feature Extraction of both MRI and CT images
}

\author{
L. Malliga
}

\begin{abstract}
Design of a common methodology for the diagnosis of different image types is the objective of the work presented in this paper. The software is developed and can be used to diagnose MRI and CT images by the laboratory technician The paper presents a statistical method for the feature extraction of MRI and CT images. About thirteen features are extracted using the methodology adopted for the proposed work. The thirteen features are based on texture, shape and intensity. The data dimensionality is reduced using the Principle Component Analysis (PCA). The common features are extracted using the Gray level co-occurrence matrix method. The software is developed using MATLAB and PYTHON for IoT support.
\end{abstract}

Index Terms: MRI, CT, Principle component analysis, GLCM, texture, shape, intensity, dimensionality reduction.

\section{INTRODUCTION}

In recent years, Medical Resonance Imaging (MRI) and Computer Tomography (CT) image had been used for detecting the neurological abnormalities and diagnosing the hemorrhage, ischemic stroke and brain tumor. Any injurious ionizing radiation does not exhibit from the MRI but it highly maintains the spatial resolution, contrast and soft tissue differentiations. Based on these features of MRI, it is widely used in clinical and surgical purpose. The MRI images are specially used to detect the brain tumors. Another brain disease called hemorrhage which is caused by blood bleeding in the brain. On the other hand, ischemic stroke is caused by the blockage of blood flow in the brain. CT scans offers more accurate data with reduced scanning time. So that, CT scans are mainly used to diagnose the hemorrhage and stroke (Rupal Snehkunj et al 2018). Therefore, processing of MRI and CT scan images is known as the medical image processing which is used to detect abnormality condition of human body. The image processing algorithm consists of four main steps such as image capture, image enhancement, image segmentation and feature extraction. Image capture performs the collection of medical images (both normal and abnormal conditions). Image enhancement modifies the image properties such as contrast and sharpening. This is best suited for next step of processing or analyzing. Image segmentation is performed after the completion of image enhancement process. It is used to dividing a single image into a set of pixels. The set of pixels is also known as super-pixels. The location of object and boundaries (lines, curves, etc) are identified by image segmentation process. In other words, image segmentation is assigned a label to each

Revised Manuscript Received on 14 August, 2019.

L.Malliga, Professor, Department of ECE, Malla Reddy EngineeringCollege for Women, Secundrabad, India pixel in the image. The same labeled pixels share the common features.

The essential step in the image processing algorithm is feature extraction. Feature extraction is a division of dimension reduction in a tradition classification approach. In image processing algorithm, certain visual property (color, shape and texture) is considered as the feature of the image. These features can be common to whole image or particular region of the image. A number of methods are available for feature extraction. In this paper, features of MRI/CT images such as contrast, correlation, entropy, energy, etc., are extracted by using statistical approaches. In this paper, section II represents the detailed survey of the feature extraction methods, section III represents the statistical approaches such as PCA and GLCM for feature extraction, Section IV represents the analysis of various features extracted by PCA and GLCM and conclusion is represented in section $\mathrm{V}$.

\section{Literature SURVEY}

C. Bhuvaneswari et al 2014 presented by a research of various feature extraction and selection methods for classifications of lung images were showed. In lung disease diagnosis, chest radiology has the most common procedure. Feature extraction was done with Gabor filter, Walsh hadamard transform. And also feature selection was done with Correlation based feature selection (CFS), Principle component analysis (PCA). Finally, through use of Naïve Bayes, J 48, K-Nearest Neighbor(KNN) and Multi-Layer Perception Neural Network.

Content-based image retrieval (CBIR) paradigm to enhance computed tomographic colonography computer-aided detection (CTCCAD) is presented by javed M.Aman et al 2010. In this paper, they appraise the performance of our system with both digital colon phantoms and detections. Scale-invariant feature transform (SIFT) methods used in the research. Then refers to bag-of-words model to combing the features and distinguish 3D images of CTCCAD detections. As the results, shows the difference between the common structure and colonography.

In this paper, aims to discover a novel prior knowledge retrieval and representation paradigm, called adaptive prior features assisted restoration algorithm. The purpose of this algorithm, the low-dose lung CT images were restored the capturing local features from the FdCT scan adaptively. The valuable structure features in 


\section{A Novel Statistical Based Methodology for The Feature Extraction of both MRI and CT images}

full-dose computed tomography (FdCT) scans can be utilized as prior knowledge for low-dose CT (LdCT) imaging presented by Yuanke Zhang et al 2017. The principle component analysis (PCA) incorporated with construction of an offline training database and online patch-search scheme that improves the research. By using the principle features to remove the noisy target patch and in depth texture could be secured. CT scans of patients with lung cancer is validates to the effectiveness of this algorithm.

A constructive tool for Alzheimer's disease (AD) diagnosis is structural magnetic resonance image (MRI). At a single point, use images to finding a conventional MRI-based AD diagnosis. A longitudinal study is more sensitive in detecting early pathological changes of $\mathrm{AD}$, making it more favorable for accurate diagnosis. Jun Zhang et al 2017. presented by a landmark-based feature extraction method for $\mathrm{AD}$ diagnosis using longitudinal structural MR images. Automatically discover the discriminative landmark from the whole brain training images, and then the testing images are capably localized using fat landmark detection method without participation of nonlinear registration and tissue segmentation. A high-level statistical spatial features and contextual longitudinal features are further extracted based on those detected landmarks. An experimental result on the ADNI database proves the superior performance and efficiency of the present method. Yinghan Fang et al 2010 analyzed by a limited non-optimal suppression improved method based on the Zernike moments. For the liver CT images sub-pixel edge features are extracted by using the combining of Sobel operator with Zernike moments operator. By improves accuracy of feature extraction with the large number of experiments and also very fast speed of extraction.

Wenlu Yang et al 2011 analyzed a method based on independent component analysis (ICA) feature extraction method used to extract the MRI images and combing with SVM classifier for $\mathrm{AD}, \mathrm{MCI}$ and $\mathrm{HC}$ subjects. Ankit Vidyarthi and Namita Mittal 2017 refer to a new texture based feature extraction algorithm is presented for extracting relevant and informative features from brain MR Images having tumor. Texture objects to form texture index matrixes with using high pass and low pass spiral filters. And then the resultant matrixes used to generate the Texture Co-occurrence Matrix (TOM). Finally, extract the spatial and spectral domain features with the help of TOM to forms the hybrid set by the brain MRI classification. In this paper Hsin-Yi Tsai et al 2017 presents a new paradigm of Graphic processing unit (GPU) accelerated method to parallelize extraction of features based on GLCM. GLCM is most widely used extraction method. The GLCM measures the spatial relationships between pixels and is used in computing second-order statistics. Experimental tests on MRI brain images exhibits the presented results are very efficient and superior to its serial counterpart.
Yosefina Finsensia Riti et al 2016 presented an aim of identify the morphological characteristics of regular and irregular margins through feature extraction method. The image processing distributed into some stages express that the segmentation with Otsu method, feature extraction with some features like convexity, solidity, circularity, and compactness, and the last is classification through Multi-Layer Perceptron (MLP). In this paper Md Shamim Reza and Jinwen Ma 2016 presented by the two features extraction approaches, which integrate with the extracted features of PCA and ICA through some statistical criterion. Feature extraction is important role in the field of machine learning, pattern recognition and image processing. Also this extraction methods are increases the performance of the classifiers. Finally the results are more effective than the other classifiers. Tri Huynh et al 2016 presented estimating CT image from MRI data using structural random forest model. In which they used a multi-scale feature extraction method. At each location, the feature vector is comprised of the spatial coordinates of the location and also the features extracted from an image patch centered at that location with fixed size across all scales. The research outcomes are shows that in various scenarios which provide accurate predict CT images. Corey B. Hart and William J. Rose 2013 presented a Visual Feature Extraction from Voxel Weighted Averaging of Stimulus Images in 2 fMRI Studies. During appearance of various data set in which they identify a subset of relevant voxels and it perform code for covarying object features. Through a technique voxel-weighted averaging, they isolate image filters and voxels act to implement. This method provides the significant results.

In this paper, a statistical structure analysis based tumor segmentation scheme is presented by Jayashri Joshi and Anuradha Phadke 2010, which focuses on the structural analysis on both tumorous and normal tissues. The textural features have been extracted using co-occurrence matric approach like GLCM. The number of features reduces to only significant component using the analysis of level of correlation. An artificial neural network and fuzzy c-means are used for classification. Ada and Rajneet Kaur 2013 analyzed by features are extracted using principle component analysis and Histogram Equalization is used for preprocessing of the CT images for detection of lung cancer. If detected early stages it reduce the risk of invasive surgery and many treatments. Shiv Ram Dubey et al 2015 presented a new image feature description based on the local wavelet pattern (LWP) in which they used for each pixel of the CT image through the relationship of Centre pixel with the local neighboring information. This method tested the performance of the present method over three CT image databases in terms of the precision and recall. The experimental results are 
outperforms than other methods.

\section{FEATURE EXTRACTION OF MRI/CT IMAGES}

\section{A.Types of Features}

The most important features of the images are extracted by the feature extraction process. The extracted feature is representative of the various classes of objects. Generally the features are classified into three different categories is shown in Table 1. The classifier accepts the selected feature as input and then performs the classification to detect the normal/abnormal conditions.

\section{B.Mathematical analysis for PCA Based Feature Extraction}

Principal Component Analysis (PCA) is a statistical approach which is used to minimize the data dimensionality. The high dimensional data is minimized to lower dimensional data by PCA and then least square sense in the data is projected. The PCA confines huge principal variability in the data and discards the small variability. The reduction of dimensionality is done by discovering a novel set of variables which is smaller than the origin variable set. Even though it extracts the confusing data from the image, PCA holds the most of the image's information. Hence, PCA is an easy and non-parametric method for dimension reduction. So that $\mathrm{PCA}$ is most suited technique for the feature extraction of image data. Principal Component Analysis is widely used in medical image processing, pattern recognition and the data dimension reduction methods. The mathematical expression for PCA is followed by equation (1) - (5).

1) The image can be represented by a data matrix $Y$, then the mean of $\mathrm{Y}$ is expressed by equation (1) and covariance is calculated from equation (2).

Mean $\mu=E\{Y\}$

Covariance $\mathrm{R}=\operatorname{Cov}\{\mathrm{Y}\}=\mathrm{E}\left\{(\mathrm{Y}-\mu)(\mathrm{Y}-\mu)^{\mathrm{T}}\right\}$

2) The Eigen vectors can be denoted as $e_{1}, e_{2}, \ldots, e_{N}, i=1,2, \ldots$ , $N$ of the covariance $\mathrm{R}$ and the Eigen value is represented as $\lambda_{\mathrm{i}}$. The Eigen values are counted and then arranged in a descending order. The equation (3) is used to solve the $\mathrm{R}$ by SVD (Singular Value Decomposition) method.

$$
|\lambda I-R|=0
$$

The Eigen values $\lambda_{1} \geq \lambda_{2} \geq \Lambda, \geq \lambda_{p} \geq 0$ and their eigenvector $e_{i}$ $(\mathrm{i}=1,2, \Lambda, \mathrm{p})$ are obtained by using this SVD method. The Eigen value $\lambda_{\mathrm{i}}$ is selected to acquire the principal component. The value of $\mathrm{M}$ is used to count the Eigen value

$$
\sum_{i=1}^{M} \lambda_{i} / \sum_{i=1}^{N} \lambda_{i}
$$

The collective portion (about 85\%) of the image is extracted as the principal component by selecting the first $\mathrm{M}$ eigen value.

3) Projected the data to a lower dimension subspace

$$
\mathrm{P}=\mathrm{W}^{\mathrm{T}} \mathrm{X}
$$

The number of variables or dimension from $n$ to $M(M \ll n)$ is reduced by using $\mathrm{M}$ eigen values. The PCA is the best way to analyze the linear combination of variables. For these reasons, PCA is suggested for feature extraction and dimension reduction process. In this paper, we implement the PCA for dimensionality reduction and feature extraction. The process involved in the PCA based feature extraction of $\mathrm{MRI} / \mathrm{CT}$ images are as follows,

\section{1) PCA to reduce dimension of an image}

The high dimension matrix $\mathrm{V}$ which consists of information about training set images. The basic principle of the PCA is to minimize the dimension of the image and keep the information as it possible. This information is used to classify the important parameter of the image and then new set of uncorrelated variables are created by converting the original image. The important features are extracted by performing the PCA on data matrix V. This is done by following two steps.

a) Remove the DC component - In this step, the mean value of the MRI/CT scan image is considered as the DC component and it holds the general information. The data is simplified and analyzed by reducing the DC component.

b) Matrix $\mathrm{W}$ is calculated from the equation (5). The matrix $\mathrm{W}$ contains the Eigen vectors $\mathrm{e}_{\mathrm{i}}$.

\section{2) Calculate feature image}

By using matrix $\mathrm{W}$, we can calculate the features of medical image in PCA method. $\mathrm{W}$ is also known as the feature detector matrix.

$$
\mathrm{m}_{1}(\mathrm{x}, \mathrm{y})=\left(\mathrm{w}_{\mathrm{i}}-\mathrm{i}\right)(\mathrm{x}, \mathrm{y})=\sum_{\mathrm{j}=2}^{\mathrm{N}} \sum_{\mathrm{k}=2}^{\mathrm{N}} \mathrm{w}_{\mathrm{i}}(\mathrm{j}, \mathrm{k}) \mathrm{Y}_{\mathrm{i}}(\mathrm{x}+\mathrm{j}, \mathrm{y}+\mathrm{k})
$$

\section{C.Feature Extraction using GLCM approach}

Gray level co-occurrence matrix (GLCM) is well known method for extracting the texture based features. The relationship between the pixels is established by the GLCM by processing the second order statistics in the image. For this processing, two pixels are taken in the image. The frequency combination of theses selected pixels are measured by the GLCM. In other words, GLCM characterize the frequency formation of the pixels. The $\mathrm{M}^{*} \mathrm{M}$ matrix is used to represent the GLCM properties such as grayscale of an image. The frequency components of the selected pixels are used to determine the elements in the matrix. Based on the nearest pixels, the chosen two pixels are varied. The gray values of the matrix elements are used to measure the second order statistical probability. The analyzed transient matrix is huge when the intensity values are broad. Because of this process, the time consuming is significantly reduced.

Generally GLCM is very useful for extracting the features like autocorrelation, contrast, correlation, entropy, homogeneity, mean, standard deviation, variance, Kurtosis and skewness. The properties of the image are successfully represented by GLCM feature matrix. 


\section{EXPERIMENTAL RESUlts}

\section{A.Data Analysis}

The dataset is acquired from "kaggle" database. It consists variety of medical images (CT, MRI and ultrasound images) based on the different patient age. It contains 475 series from 69 different patients. This is very useful for analyzing and identifying the image textures, statistical patterns and features of the medical images.

\section{B.Parameter measures}

\section{The Intensity Based Feature}

The intensity based feature is most commonly used features compared to texture based features in image processing algorithm. Mean, standard deviation, variance, median, skewness and kurtosis is considered as the intensity based features. The two dimensional function of the image is denoted by $\mathrm{f}(\mathrm{a}, \mathrm{b})$, intensity level is denoted by $\mathrm{h}(\mathrm{i}), \mathrm{N}$ is denoted by the total number of gray levels in the entire image and $\mathrm{p}(\mathrm{i})$ denotes the probability density. The mathematical expression of $\mathrm{p}(\mathrm{i}), \mathrm{h}(\mathrm{i}), \mathrm{f}(\mathrm{a}, \mathrm{b})$ and $\chi(\mathrm{i}, \mathrm{j})$ are expressed in equation (7) - (10).

$$
\begin{aligned}
& p(i)=\frac{h(i)}{N_{a} N_{b}}, \quad i=0,1,2, \ldots . . N-1 \\
& h(i)=\sum_{x=0}^{N} \sum_{y=0}^{-1 N} \chi(f(a, b), i) \quad i=0,1,2, \ldots . . N-1 \\
& \mathrm{f}(\mathrm{a}, \mathrm{b})=\left|\begin{array}{ccrrc}
\mathrm{f}(0,0) & \mathrm{f}(0,1) & \mathrm{f}(0,2) & \ldots . . & \mathrm{f}\left(0, \mathrm{~N}_{\mathrm{b}}-1\right) \\
\mathrm{f}(1,0) & \mathrm{f}(1,1) & \mathrm{f}(1,2) & \ldots \ldots & \mathrm{f}\left(1, \mathrm{~N}_{\mathrm{b}}-1\right) \\
\mathrm{f}(0,0) & \mathrm{f}(0,1) & \mathrm{f}(0,2) & \ldots \ldots & \mathrm{f}\left(0, \mathrm{~N}_{\mathrm{b}}-1\right) \\
\ldots & \ldots & \ldots & \ldots . . & \ldots \\
\mathrm{f}\left(\mathrm{N}_{\mathrm{a}}-1,0\right) & \mathrm{f}\left(\mathrm{N}_{\mathrm{a}}-1,1\right) & \ldots \ldots . & \ldots . . & \mathrm{f}\left(\mathrm{N}_{\mathrm{a}}-1, \mathrm{~N}_{\mathrm{b}}-1\right)
\end{array}\right|
\end{aligned}
$$

$$
\chi(\mathrm{i}, \mathrm{j})= \begin{cases}1 ; & \mathrm{i}=\mathrm{j} \\ 0 ; & \mathrm{i} \neq \mathrm{j}\end{cases}
$$

\section{- Mean}

Mean is defined as the average level of intensity of image. Equation (11) expresses the mathematical form of the mean. It clearly shows that the mean is a function probability density.

$$
\text { Mean } \mu=\sum_{i=0}^{N-1} i, p(i)
$$

\section{- Standard Deviation}

The mean value of the pixels and their probability densities are used to measure the standard deviation which is shown in equation (12).

$$
\text { SD or } \sigma=\sqrt{\sum_{i=0}^{N-1}(i-\mu)^{2} \cdot p(i)}
$$

\section{- Entropy}

The uncertainty in the random variable is measured by the entropy. It depends on the probability density p(i) and the mathematical form of entropy is shown in equation (13).

$$
\text { Entropy or } E n=-\sum_{i=0}^{N-1} p(i) \log _{2}[p(i)]
$$

\section{- Variance}

The variation in the intensity is measured with the help of variance. It is also calculated by squaring the standard deviation. Equation (14) shows the expression of variance.

$$
\text { Variance or } \sigma^{2}=\sum_{i=0}^{N-1}(i-\mu)^{2} \cdot p(i)
$$

\section{- Kurtosis}

The histogram flatness is measured by kurtosis. Equation (15) expresses the mathematical form kurtosis which depends on the standard deviation, mean and probability density.

$$
\text { Kurtosis or } \mu^{4}=\sigma \sum_{i=0}^{N-1}\left((i-\mu)^{4} \cdot p(i)\right)-3
$$

\section{- Skewness}

Symmetry of an image is defined by the skewness. It is denoted by $\mu^{3}$ and is shown in equation (16). The relationship between the mean, histogram and the skewness is clearly expressed in equation (17).

$$
\begin{aligned}
& \text { Skewness or } \mu^{3}=\sigma^{-3} \sum_{\mathrm{i}=0}^{\mathrm{N}-1}\left((\mathrm{i}-\mu)^{3} \cdot \mathrm{p}(\mathrm{i}) \quad\right. \text { (16) } \\
& \text { Skewness or } \mu^{3}=\mid \begin{array}{l}
\mu^{3}<0 ; \text { Histogram below than mean } \\
\mu^{3}=0 ; \text { Histogram is equal to mean } \\
\mu^{3}>0 ; \text { Histogram above than to mean }
\end{array}
\end{aligned}
$$

\section{Texture Based Feature}

The higher order description of an image is offered by the texture features. It provides the details about spatial distribution of tonal variations or gray tones. The texture based feature extraction includes the homogeneity and similar regions of an image. The gray matter, white matter, cerebrospinal fluid and tumor region are classified from the MRI by this feature.

\section{- Inverse Difference Moment (IDM)}

The local homogeneity of an image is calculated by IDM. Equation (18) shows the mathematical form of IDM.

$\operatorname{IDM}=\sum_{\mathrm{i}=0}^{\mathrm{N}-1} \sum_{\mathrm{i}=0}^{\mathrm{N}-1} \frac{1}{1+(\mathrm{i}-\mathrm{j})^{2}} \mathrm{p}(\mathrm{i}, \mathrm{j})$

\section{- Contrast}

The intensity variation of threshold and its nearest pixel is determined by contrast. The contrast is mathematically expressed in equation (19).

Contrast $=\sum_{\mathrm{n}=0}^{\mathrm{N}-1} \sum_{\mathrm{i}=0}^{\mathrm{N}-1} \sum_{\mathrm{j}=0}^{\mathrm{N}-1} \mathrm{p}(\mathrm{i}, \mathrm{j})^{2}$

\section{- Correlation}

Equation (20) expresses the analytical form of correlation. It is used to measure the relationship between the threshold and nearest pixel.

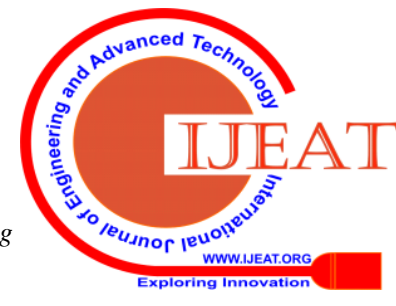


Correlation $=\frac{1}{\sigma_{\mathrm{a}} \sigma_{\mathrm{b}}} \sum_{\mathrm{i}=0}^{\mathrm{N}-1} \sum_{\mathrm{j}=0}^{\mathrm{N}-1}(\mathrm{i}, \mathrm{j}) \cdot \mathrm{p}(\mathrm{i}, \mathrm{j})^{2}-\mu_{\mathrm{a}} \mu_{\mathrm{b}}$

\section{- Energy}

Equation (21) represents the mathematical form of energy. Homogeneity is calculated by the energy. It is also called as angular second moment or uniformity.

Energy $=\sum_{\mathrm{i}=0}^{\mathrm{N}-1} \sum_{\mathrm{j}=0}^{\mathrm{N}-1} \mathrm{p}(\mathrm{i}, \mathrm{j})^{2}$

\section{C.Implementation results}

\begin{tabular}{|c|c|c|c|c|c|}
\hline $\begin{array}{l}\text { Feat } \\
\text { ures }\end{array}$ & $\begin{array}{c}\text { CT_ima } \\
\text { ge1 }\end{array}$ & $\begin{array}{c}\mathrm{CT} \_\mathrm{i} \\
\text { mage } \\
2\end{array}$ & $\begin{array}{c}\text { CT_i } \\
\text { mage3 }\end{array}$ & $\begin{array}{c}\mathrm{CT} \_\mathrm{i} \\
\text { mage } \\
4\end{array}$ & $\begin{array}{c}\text { CT_im } \\
\text { age5 }\end{array}$ \\
\hline $\begin{array}{c}\text { Mea } \\
\mathrm{n}\end{array}$ & $\begin{array}{c}005728 \\
41\end{array}$ & $\begin{array}{c}0.003 \\
55526\end{array}$ & 3004 & $\begin{array}{l}0.005 \\
96506\end{array}$ & 16 \\
\hline $\begin{array}{l}\text { Stan } \\
\text { dard } \\
\text { Devi } \\
\text { ation }\end{array}$ & $\begin{array}{c}0.089631 \\
8\end{array}$ & $\begin{array}{l}0.089 \\
7443\end{array}$ & $\begin{array}{c}0.0897 \\
492\end{array}$ & $\begin{array}{c}0.089 \\
6164\end{array}$ & $\begin{array}{c}0.08960 \\
51\end{array}$ \\
\hline $\begin{array}{c}\text { Entr } \\
\text { opy }\end{array}$ & 2.85839 & $\begin{array}{c}3.485 \\
96\end{array}$ & $\begin{array}{c}3.3767 \\
4\end{array}$ & $\begin{array}{c}3.195 \\
93\end{array}$ & 3.36316 \\
\hline RMS & $\begin{array}{c}0.089802 \\
7 \\
\end{array}$ & $\begin{array}{l}0.089 \\
8027 \\
\end{array}$ & $\begin{array}{c}0.0898 \\
027 \\
\end{array}$ & $\begin{array}{l}0.089 \\
8027 \\
\end{array}$ & $\begin{array}{c}0.08980 \\
27 \\
\end{array}$ \\
\hline $\begin{array}{l}\text { Vari } \\
\text { ance }\end{array}$ & $\begin{array}{c}0.008041 \\
59 \\
\end{array}$ & $\begin{array}{c}0.008 \\
04076\end{array}$ & $\begin{array}{c}0.0080 \\
4505\end{array}$ & $\begin{array}{c}0.008 \\
03294 \\
\end{array}$ & $\begin{array}{c}0.00803 \\
152\end{array}$ \\
\hline $\begin{array}{c}\text { Smo } \\
\text { othn } \\
\text { ess }\end{array}$ & 0.955176 & $\begin{array}{c}0.929 \\
704\end{array}$ & $\begin{array}{c}0.9273 \\
24\end{array}$ & $\begin{array}{c}0.956 \\
878\end{array}$ & 0.958 \\
\hline $\begin{array}{l}\text { Kurt } \\
\text { osis }\end{array}$ & 14.6479 & $\begin{array}{c}12.14 \\
01 \\
\end{array}$ & $\begin{array}{c}13.439 \\
9 \\
\end{array}$ & $\begin{array}{c}16.37 \\
74 \\
\end{array}$ & 13.4946 \\
\hline $\begin{array}{c}\text { Ske } \\
\text { wnes } \\
\text { s }\end{array}$ & 1.16069 & $\begin{array}{c}0.793 \\
108\end{array}$ & $\begin{array}{c}1.0660 \\
1\end{array}$ & $\begin{array}{c}1.624 \\
52\end{array}$ & 1.30227 \\
\hline IDM & $\begin{array}{c}-0.13723 \\
8 \\
\end{array}$ & $\begin{array}{l}0.061 \\
0352 \\
\end{array}$ & $\begin{array}{c}0.7508 \\
51 \\
\end{array}$ & $\begin{array}{l}-0.19 \\
2934 \\
\end{array}$ & 1.3672 \\
\hline $\begin{array}{c}\text { Cont } \\
\text { rast }\end{array}$ & 0.293382 & $\begin{array}{c}0.258 \\
065 \\
\end{array}$ & $\begin{array}{c}0.2694 \\
66\end{array}$ & $\begin{array}{c}0.312 \\
57 \\
\end{array}$ & $\begin{array}{c}0.29783 \\
1\end{array}$ \\
\hline $\begin{array}{c}\text { Corr } \\
\text { elati } \\
\text { on }\end{array}$ & 0.172569 & $\begin{array}{c}0.121 \\
463\end{array}$ & $\begin{array}{c}0.1172 \\
86\end{array}$ & $\begin{array}{c}0.131 \\
583\end{array}$ & 0.16499 \\
\hline $\begin{array}{c}\text { Ener } \\
\text { gy }\end{array}$ & 0.785858 & $\begin{array}{c}0.806 \\
757 \\
\end{array}$ & $\begin{array}{c}0.7691 \\
2 \\
\end{array}$ & $\begin{array}{c}0.779 \\
06 \\
\end{array}$ & $\begin{array}{c}0.77808 \\
2 \\
\end{array}$ \\
\hline $\begin{array}{c}\text { Hom } \\
\text { ogen } \\
\text { eity }\end{array}$ & 0.940369 & $\begin{array}{c}0.945 \\
157\end{array}$ & $\begin{array}{c}0.9358 \\
9\end{array}$ & $\begin{array}{c}0.938 \\
017\end{array}$ & $\begin{array}{c}0.93662 \\
9\end{array}$ \\
\hline
\end{tabular}

The whole implementation was held in Matlab environment. Sample of five CT and MRI images are taken for analyzing the features such as mean, standard deviation, entropy, RMS, variance, smoothness, kurtosis, skewness, IDM, contrast, correlation, energy and homogeneity are extracted by PCA and GLCM approaches. Table 2 and Table 3 show the various feature extraction of CT and MRI images by PCA algorithm. Similarly Table 4 and Table 5 show the various feature extraction of CT and MRI images by GLCM algorithm.
Figure 1 shows the performance comparison of PCA and GLCM algorithm for extracting features such as standard deviation, entropy, RMS, IDM, contrast and Figure 2 represents the performance comparison of these two algorithms for extracting the CT image features like correlation, energy, homogeneity, smoothness. Figure 3 shows the extraction of Mean, Variance, Kurtosis and Skewness of the CT image by both PCA and GLCM methods. Figure 4, 5 and 6 shows the feature extraction of MRI images by PCA and GLCM.

Table 2 Feature analysis of CT images using PCA algorithm

\begin{tabular}{|c|c|c|c|c|c|}
\hline $\begin{array}{c}\text { Featu } \\
\text { res }\end{array}$ & MRI_1 & MRI_2 & MRI_3 & MRI_4 & $\begin{array}{c}\text { MRI } \\
\_5\end{array}$ \\
\hline Mean & $\begin{array}{c}0.00663 \\
854\end{array}$ & $\begin{array}{c}0.9222 \\
28\end{array}$ & $\begin{array}{c}0.00524 \\
708\end{array}$ & $\begin{array}{c}0.00523 \\
89\end{array}$ & $\begin{array}{c}0.00 \\
4096 \\
77\end{array}$ \\
\hline $\begin{array}{c}\text { Stand } \\
\text { ard } \\
\text { Devia } \\
\text { tion }\end{array}$ & $\begin{array}{c}0.08956 \\
9\end{array}$ & $\begin{array}{c}0.0897 \\
119\end{array}$ & $\begin{array}{c}0.08966 \\
13\end{array}$ & $\begin{array}{c}0.08966 \\
18\end{array}$ & $\begin{array}{c}0.08 \\
9721 \\
2\end{array}$ \\
\hline $\begin{array}{c}\text { Entro } \\
\text { py }\end{array}$ & 3.19858 & $\begin{array}{c}2.8635 \\
6 \\
\end{array}$ & 3.14972 & 3.31407 & $\begin{array}{l}2.73 \\
665 \\
\end{array}$ \\
\hline RMS & $\begin{array}{c}0.08980 \\
27\end{array}$ & $\begin{array}{c}0.0898 \\
027\end{array}$ & $\begin{array}{c}0.08980 \\
27\end{array}$ & $\begin{array}{c}0.08980 \\
27\end{array}$ & $\begin{array}{c}0.08 \\
9802 \\
7\end{array}$ \\
\hline $\begin{array}{l}\text { Varia } \\
\text { nce }\end{array}$ & $\begin{array}{c}0.00803 \\
861\end{array}$ & $\begin{array}{c}0.0080 \\
4999\end{array}$ & $\begin{array}{c}0.00805 \\
6\end{array}$ & $\begin{array}{c}0.00803 \\
685\end{array}$ & $\begin{array}{c}0.00 \\
8050 \\
03 \\
\end{array}$ \\
\hline $\begin{array}{l}\text { Smoot } \\
\text { hness }\end{array}$ & $\begin{array}{c}0.96108 \\
2\end{array}$ & $\begin{array}{c}0.9411 \\
03\end{array}$ & $\begin{array}{c}0.95126 \\
5\end{array}$ & $\begin{array}{c}0.95119 \\
3\end{array}$ & $\begin{array}{l}0.93 \\
8424\end{array}$ \\
\hline $\begin{array}{c}\text { Kurto } \\
\text { sis }\end{array}$ & 7.38538 & $\begin{array}{c}20.895 \\
8\end{array}$ & 9.18677 & 6.84522 & $\begin{array}{c}9.05 \\
65 \\
\end{array}$ \\
\hline $\begin{array}{c}\text { Skew } \\
\text { ness }\end{array}$ & $\begin{array}{c}0.75939 \\
5 \\
\end{array}$ & $\begin{array}{c}1.9143 \\
3\end{array}$ & $\begin{array}{c}0.86114 \\
3\end{array}$ & $\begin{array}{c}0.69783 \\
7\end{array}$ & $\begin{array}{r}0.80 \\
7729 \\
\end{array}$ \\
\hline IDM & $\begin{array}{c}0.94835 \\
6\end{array}$ & $\begin{array}{c}0.1340 \\
08\end{array}$ & $\begin{array}{c}-0.0519 \\
309\end{array}$ & $\begin{array}{c}0.98588 \\
6\end{array}$ & $\begin{array}{c}-0.3 \\
2101 \\
4\end{array}$ \\
\hline $\begin{array}{c}\text { Contr } \\
\text { ast }\end{array}$ & $\begin{array}{c}0.28281 \\
4\end{array}$ & $\begin{array}{c}0.3189 \\
66\end{array}$ & $\begin{array}{c}0.28170 \\
2\end{array}$ & $\begin{array}{c}0.25111 \\
2\end{array}$ & $\begin{array}{l}0.27 \\
6696 \\
\end{array}$ \\
\hline $\begin{array}{c}\text { Correl } \\
\text { ation }\end{array}$ & $\begin{array}{c}0.05738 \\
66\end{array}$ & $\begin{array}{c}0.1449 \\
19\end{array}$ & $\begin{array}{c}0.09510 \\
96\end{array}$ & $\begin{array}{c}0.08815 \\
95\end{array}$ & $\begin{array}{l}0.14 \\
4308 \\
\end{array}$ \\
\hline $\begin{array}{c}\text { Energ } \\
\mathrm{y}\end{array}$ & $\begin{array}{c}0.72545 \\
5\end{array}$ & $\begin{array}{c}0.7992 \\
71\end{array}$ & $\begin{array}{c}0.76073 \\
4\end{array}$ & $\begin{array}{c}0.74282 \\
2\end{array}$ & $\begin{array}{l}0.76 \\
254 \\
\end{array}$ \\
\hline $\begin{array}{c}\text { Homo } \\
\text { geneit } \\
y\end{array}$ & $\begin{array}{c}0.92222 \\
8\end{array}$ & $\begin{array}{c}0.9435 \\
23\end{array}$ & $\begin{array}{c}0.93141 \\
5\end{array}$ & $\begin{array}{c}0.92844 \\
4\end{array}$ & $\begin{array}{l}0.93 \\
1864\end{array}$ \\
\hline
\end{tabular}

Table 3 Feature analysis of MRI images using PCA algorithm

Table 4 Feature analysis of CT images using GLCM approach

\begin{tabular}{|c|c|c|c|c|c|}
\hline $\begin{array}{c}\text { Feat } \\
\text { ures }\end{array}$ & $\begin{array}{c}\text { CT_i } \\
\text { mage1 }\end{array}$ & $\begin{array}{c}\text { CT_i } \\
\text { mage }\end{array}$ & $\begin{array}{c}\text { CT_i } \\
\text { mage }\end{array}$ & $\begin{array}{c}\text { CT_i } \\
\text { mage4 }\end{array}$ & $\begin{array}{c}\text { CT_ima } \\
\text { ge5 }\end{array}$ \\
\hline
\end{tabular}


A Novel Statistical Based Methodology for The Feature Extraction of both MRI and CT images

\begin{tabular}{|c|c|c|c|c|c|}
\hline $\begin{array}{c}\text { Mea } \\
\mathrm{n}\end{array}$ & $\begin{array}{c}.0830 \\
\mathrm{e}-04 \\
\end{array}$ & $\begin{array}{l}6.988 \\
3 e-04 \\
\end{array}$ & $\begin{array}{c}0.002 \\
0 \\
\end{array}$ & 0.0018 & 0.0012 \\
\hline $\begin{array}{l}\text { Feat } \\
\text { ures }\end{array}$ & $\begin{array}{c}\text { MRI_- } \\
1\end{array}$ & $\begin{array}{c}\text { MRI } \\
2 \\
\end{array}$ & $\begin{array}{c}\text { MRI } \\
3 \\
\end{array}$ & MRI_4 & $\begin{array}{c}\text { MRI_ } \\
5\end{array}$ \\
\hline $\begin{array}{c}\text { Mea } \\
n\end{array}$ & $\begin{array}{c}4.9128 \\
\text { e-04 }\end{array}$ & $\begin{array}{l}1.414 \\
2 \mathrm{e}-04\end{array}$ & $\begin{array}{l}3.571 \\
9 \mathrm{e}-05\end{array}$ & $\begin{array}{c}6.8660 \mathrm{e}- \\
05\end{array}$ & $\begin{array}{c}7.3905 \\
\mathrm{e}-05 \\
\end{array}$ \\
\hline $\begin{array}{l}\text { Stan } \\
\text { dard } \\
\text { Devi } \\
\text { ation }\end{array}$ & 0.0105 & $\begin{array}{c}0.007 \\
8\end{array}$ & $\begin{array}{c}0.002 \\
5\end{array}$ & 0.0044 & 0.0076 \\
\hline $\begin{array}{l}\text { Entr } \\
\text { opy }\end{array}$ & 0.0551 & $\begin{array}{c}0.005 \\
9 \\
\end{array}$ & $\begin{array}{c}0.009 \\
9 \\
\end{array}$ & 0.0051 & 0.0017 \\
\hline $\begin{array}{c}\mathrm{RM} \\
\mathrm{S}\end{array}$ & 0.0036 & $\begin{array}{c}0.001 \\
9\end{array}$ & $\begin{array}{l}4.478 \\
7 \mathrm{e}-04 \\
\end{array}$ & $\begin{array}{c}9.5813 \mathrm{e}- \\
04\end{array}$ & $\begin{array}{c}9.8392 \\
\text { e-04 }\end{array}$ \\
\hline $\begin{array}{l}\text { Vari } \\
\text { ance }\end{array}$ & $\begin{array}{c}1.0925 \\
\mathrm{e}-04\end{array}$ & $\begin{array}{l}6.111 \\
0 \mathrm{e}-05 \\
\end{array}$ & $\begin{array}{l}6.193 \\
2 \mathrm{e}-06 \\
\end{array}$ & $\begin{array}{c}1.9338 \mathrm{e}- \\
05\end{array}$ & $\begin{array}{c}5.7093 \\
\mathrm{e}-05 \\
\end{array}$ \\
\hline $\begin{array}{c}\text { Smo } \\
\text { othn } \\
\text { ess }\end{array}$ & 0.9974 & $\begin{array}{c}0.991 \\
1\end{array}$ & $\begin{array}{c}0.965 \\
6\end{array}$ & 0.9818 & 0.9831 \\
\hline $\begin{array}{l}\text { Kurt } \\
\text { osis }\end{array}$ & $\begin{array}{c}1.1130 \\
\mathrm{e}+03\end{array}$ & $\begin{array}{l}3.125 \\
2 \mathrm{e}+03 \\
\end{array}$ & $\begin{array}{l}2.157 \\
1 \mathrm{e}+04 \\
\end{array}$ & $\begin{array}{c}4.7879 \mathrm{e}+ \\
03\end{array}$ & $\begin{array}{c}1.0533 \\
\mathrm{e}+04\end{array}$ \\
\hline $\begin{array}{c}\text { Ske } \\
\text { wnes } \\
\text { S } \\
\end{array}$ & $\begin{array}{c}29.572 \\
9\end{array}$ & $\begin{array}{c}55.72 \\
75\end{array}$ & $\begin{array}{c}126.9 \\
600\end{array}$ & 67.7794 & $\begin{array}{c}102.56 \\
46\end{array}$ \\
\hline IDM & 0.0059 & $\begin{array}{c}0.034 \\
5 \\
\end{array}$ & $\begin{array}{c}0.009 \\
4 \\
\end{array}$ & 0.0063 & 0.0109 \\
\hline $\begin{array}{c}\text { Cont } \\
\text { rast }\end{array}$ & 0.0024 & $\begin{array}{c}0.001 \\
4 \\
\end{array}$ & $\begin{array}{l}1.376 \\
0 \mathrm{e}-04 \\
\end{array}$ & $\begin{array}{c}4.5102 \mathrm{e}- \\
04\end{array}$ & 0.0015 \\
\hline $\begin{array}{c}\text { Corr } \\
\text { elati } \\
\text { on } \\
\end{array}$ & 0.6906 & $\begin{array}{c}0.746 \\
1\end{array}$ & $\begin{array}{c}0.653 \\
8\end{array}$ & 0.7035 & 0.7680 \\
\hline $\begin{array}{c}\text { Ener } \\
\text { gy }\end{array}$ & 0.9958 & $\begin{array}{c}0.999 \\
2 \\
\end{array}$ & $\begin{array}{c}0.999 \\
8 \\
\end{array}$ & 0.9994 & 0.9998 \\
\hline $\begin{array}{l}\text { Hom } \\
\text { ogen } \\
\text { eity }\end{array}$ & 0.9994 & $\begin{array}{c}0.999 \\
9\end{array}$ & $\begin{array}{c}1.000 \\
0\end{array}$ & 0.9999 & 1.0000 \\
\hline $\begin{array}{l}\text { Stan } \\
\text { dard } \\
\text { Devi } \\
\text { ation }\end{array}$ & 0.0208 & $\begin{array}{c}0.020 \\
4\end{array}$ & $\begin{array}{c}0.031 \\
5\end{array}$ & 0.0310 & 0.0252 \\
\hline $\begin{array}{r}\text { Entr } \\
\text { opy }\end{array}$ & 0.0297 & $\begin{array}{c}0.027 \\
3 \\
\end{array}$ & $\begin{array}{c}0.066 \\
9 \\
\end{array}$ & 0.0645 & 0.1218 \\
\hline RMS & 0.0057 & $\begin{array}{c}0.005 \\
7 \\
\end{array}$ & $\begin{array}{c}0.012 \\
7 \\
\end{array}$ & 0.0124 & 0.0110 \\
\hline $\begin{array}{l}\text { Vari } \\
\text { ance }\end{array}$ & $\begin{array}{c}4.2548 \\
\mathrm{e}-04\end{array}$ & $\begin{array}{l}4.090 \\
4 \mathrm{e}-04 \\
\end{array}$ & $\begin{array}{l}9.722 \\
6 \mathrm{e}-04 \\
\end{array}$ & $\begin{array}{c}9.4232 \\
\mathrm{e}-04\end{array}$ & $\begin{array}{c}6.2147 \mathrm{e}- \\
04\end{array}$ \\
\hline $\begin{array}{c}\text { Smo } \\
\text { othn } \\
\text { ess }\end{array}$ & 0.9982 & $\begin{array}{c}0.998 \\
2\end{array}$ & $\begin{array}{c}0.999 \\
3\end{array}$ & 0.9993 & 0.9989 \\
\hline $\begin{array}{l}\text { Kurt } \\
\text { osis }\end{array}$ & $\begin{array}{c}1.3418 \\
\mathrm{e}+03\end{array}$ & $\begin{array}{c}943.1 \\
339 \\
\end{array}$ & $\begin{array}{c}295.5 \\
930 \\
\end{array}$ & $\begin{array}{c}336.84 \\
86 \\
\end{array}$ & 738.0512 \\
\hline $\begin{array}{c}\text { Ske } \\
\text { wnes } \\
\text { S } \\
\end{array}$ & $\begin{array}{c}35.063 \\
6\end{array}$ & $\begin{array}{c}30.28 \\
11\end{array}$ & $\begin{array}{c}16.86 \\
68\end{array}$ & $\begin{array}{c}17.991 \\
6\end{array}$ & 26.2749 \\
\hline IDM & 0.0479 & $\begin{array}{c}6.610 \\
1 \\
\end{array}$ & $\begin{array}{c}6.456 \\
8 \\
\end{array}$ & 8.0170 & 0.4593 \\
\hline $\begin{array}{c}\text { Cont } \\
\text { rast }\end{array}$ & 0.0067 & $\begin{array}{c}0.006 \\
2 \\
\end{array}$ & $\begin{array}{c}0.014 \\
4 \\
\end{array}$ & 0.0156 & 0.0131 \\
\hline $\begin{array}{l}\text { Corr } \\
\text { elati }\end{array}$ & 0.8394 & $\begin{array}{c}0.837 \\
7 \\
\end{array}$ & $\begin{array}{c}0.838 \\
0 \\
\end{array}$ & 0.8246 & 0.7829 \\
\hline
\end{tabular}

\begin{tabular}{|c|c|c|c|c|c|}
\hline on & & & & & \\
\hline $\begin{array}{c}\text { Ener } \\
\text { gy }\end{array}$ & 0.9962 & $\begin{array}{c}0.997 \\
1\end{array}$ & $\begin{array}{c}0.990 \\
3\end{array}$ & 0.9917 & 0.9953 \\
\hline $\begin{array}{c}\text { Hom } \\
\text { ogen } \\
\text { eity }\end{array}$ & 0.9994 & $\begin{array}{c}0.999 \\
5\end{array}$ & $\begin{array}{c}0.998 \\
6\end{array}$ & 0.9986 & 0.9991 \\
\hline
\end{tabular}

Table 5 Feature analysis of MRI images using GLCM approach

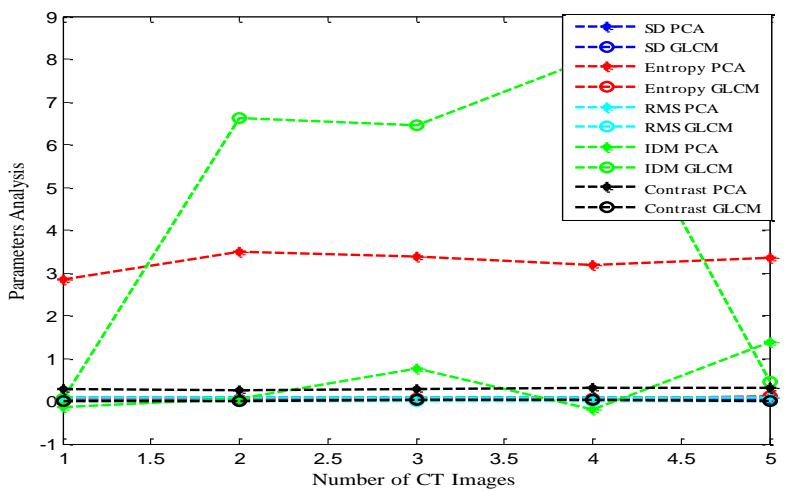

Figure 1 Performance comparison of PCA and GLCM algorithm for CT image Feature extraction (SD, Entropy, RMS, IDM, Contrast)

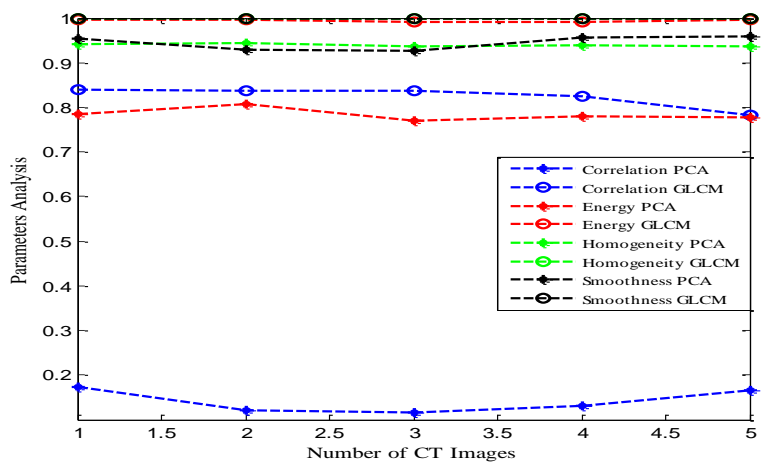

Figure 2 Performance comparison of PCA and GLCM algorithm for CT image Feature extraction (Correlation, Energy, Homogeneity, Smoothness)

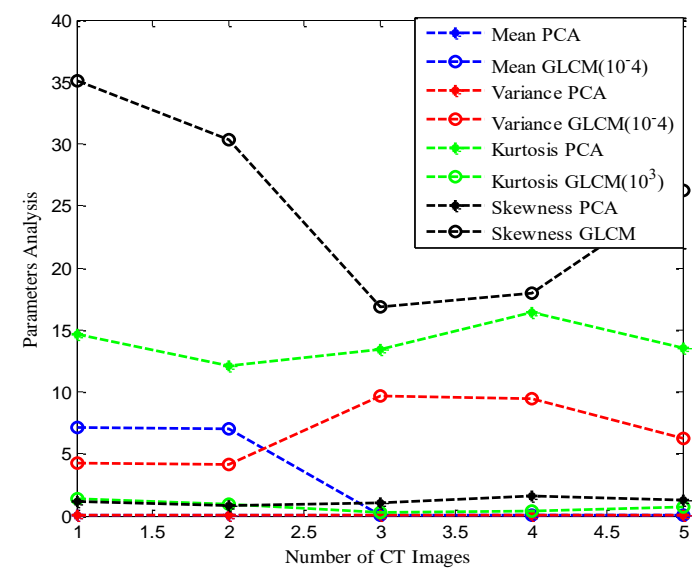

Figure 3 Performance comparison of PCA and GLCM algorithm for CT image Feature extraction (Mean, Variance, Kurtosis, Skewness)

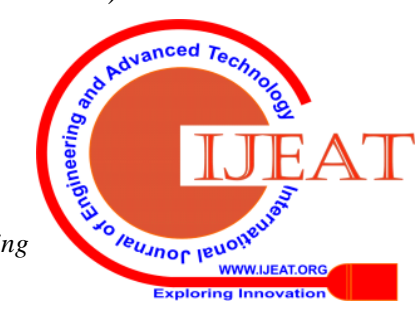




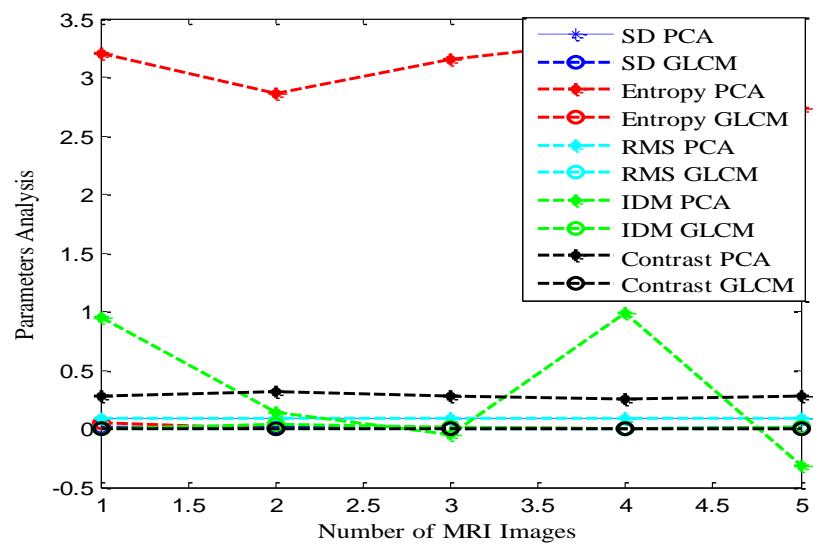

Figure 4 Performance comparison of PCA and GLCM algorithm for MRI image Feature extraction (SD, Entropy,

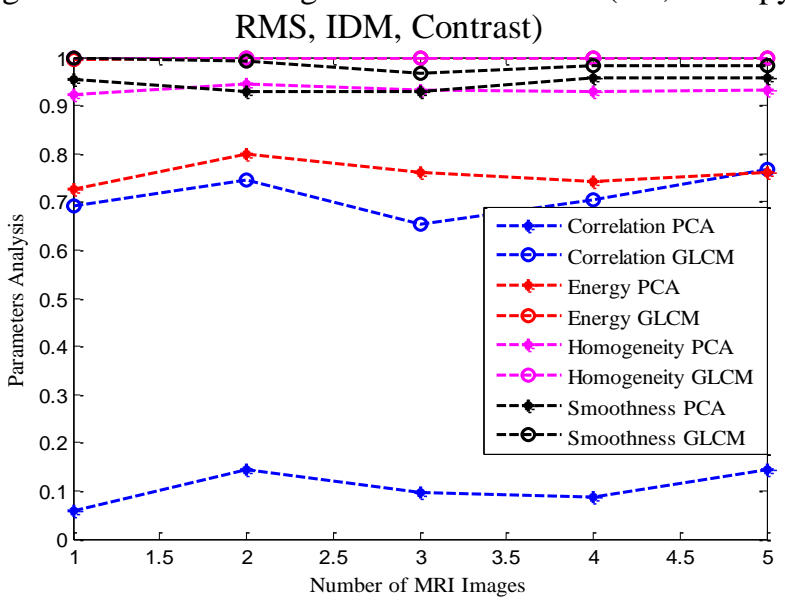

Figure 5 Performance comparison of PCA and GLCM algorithm for MRI image Feature extraction (Correlation, Energy, Homogeneity, Smoothness)

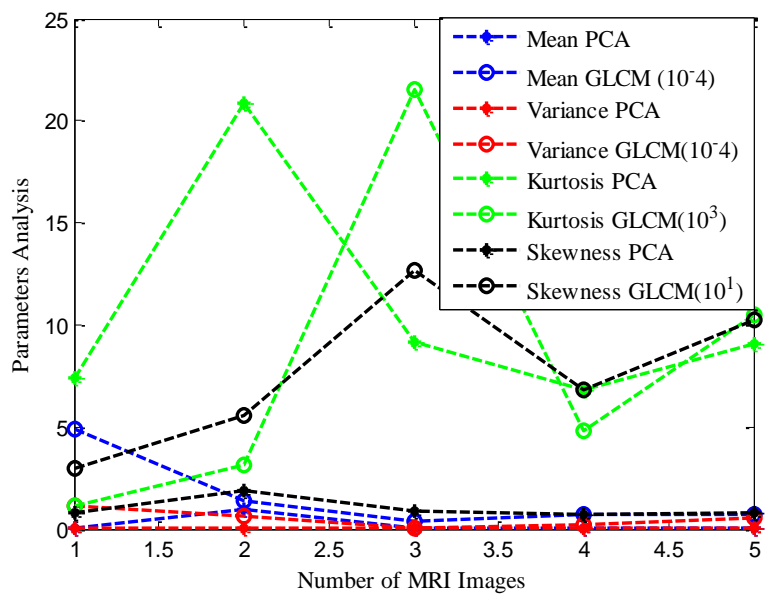

Figure 6 Performance comparison of PCA and GLCM algorithm for MRI image Feature extraction (Mean, Variance, Kurtosis, Skewness)

\section{CONCLUSION}

The paper presents the design of single software for the diagnosis of MRI and CT images, As the types are different common features are extracted using the proposed methodology. Thirteen features based on texture, shape and intensity are extracted and data dimensionality is reduced using the Principle Component Analysis (PCA). The common features are extracted using the Gray level co-occurrence matrix method. The software is developed using MATLAB and PYTHON for IoT support

\section{REFERENCES}

1. Rupal Snehkunj, Ashish N. Jani and Nalin N. Jani, "Brain MRI/CT Images Feature Extraction to Enhance Abnormalities Quantification", Indian Journal of Science and Technology, Vol. 11, No. 1, pp. 1-10, 2018.

2. C.Bhuvaneswari et al., "Performance Evaluation Of Feature Extraction And Feature Selection For Classification Of Lung Diseases," Journal of Theoretical and Applied Information Technology, vol.61, no. 2, pp. 389-394, March 2014.

3. Javed M. Aman, Jianhua Yao and Ronald M. Summers, "Content-Based Image Retrieval on CT Colonography Using Rotation and Scale Invariant Features and Bag-Of-Words Model,” IEEE international Symposium on Biomedical imaging, April 2010, pp. 1357-1360.

4. J.Surendiran1 , A.Srinivasula Reddy2 , Mohammad Jabirullah3,' Magnetically Induced Deep Brain Stimulation for Pain Relief", International Journal of Pure and Applied Mathematics Volume 119 No. 12 2018, 14373-14379 ISSN: 1314-3395.

5. Jun Zhang et al., "Alzheimer's Disease Diagnosis using Landmark-based Features from Longitudinal Structural MR Images," IEEE Journal of Biomedical and Health Informatics, vol. 21, no. 6, pp. 1607 - 1616, May 2017.

6. Yinghan Fang, Huiming Xiao and Beilei Wang, "A Sub-pixel Feature Extraction Method for CT Image Based on Zernike Moments," International Conference on Advanced computer control, March 2010, pp. 539-542.

7. Wenlu Yang et al., "Independent Component Analysis-Based Classification of Alzheimer's Disease MRI Data," Journal of Alzheimer's Disease, vol. 24, no.4, pp.775-783, 2011.

8. Ankit Vidyarthi and Namita Mittal, "Texture based feature extraction method for classification of brain tumor MRI," Journal of Intelligent \& Fuzzy Systems, vol.32, no.4, pp.2807-2818, Jan 2017.

9. Hsin-Yi Tsai et al., "GPU-Accelerated Features Extraction From Magnetic Resonance Images," Special Section On Advanced Signal Processing Methods In Medical Imaging, vol.5, pp. 22634 - 22646, Sep 2017.

10. Yosefina Finsensia Riti et al, "Feature Extraction for Lesion Margin Characteristic Classification from CT Scan Lungs Image," International Conference on Information Technology, Information Systems and Electrical Engineering (ICITISEE), pp. 54-58, Aug. 2016.

11. Md Shamim Reza and Jinwen Ma, "ICA and PCA Integrated Feature Extraction for Classification," International Conference on Signal Processing (ICSP), pp. 1084-1088, Nov 2016.

12. Tri Huynh et al., "Estimating CT Image from MRI Data Using Structured Random Forest and Auto-context Model," IEEE Transactions on Medical Imaging, vol.35, no.1, pp.1-10, Jan 2016.

13. Corey B. Hart and William J. Rose, "Visual Feature Extraction From Voxel-Weighted Averaging of Stimulus Images in 2 fMRI Studies," IEEE Transactions on Biomedical Engineering, vol. 60, no. 11, pp.3124-3130, Nov 2013.

14. Jayashri Joshi and Anuradha Phadke, "Feature Extraction and Texture Classification in MRI," International Conference [ICCT-2010], pp. 130-136, Dec 2010.

15. Ada and Rajneet Kaur, "Feature Extraction and Principal Component Analysis for Lung Cancer Detection in CT scan Images," International Journal of Advanced Research in Computer Science and Software Engineering, vol.3,no. 3, pp. 187-190, March 2013.

16. Rajesh, M., and J. M. Gnanasekar. "Path Observation Based Physical Routing Protocol for Wireless Ad Hoc Networks." Wireless Personal Communications 97.1 (2017): 1267-1289. 